\title{
The use of the radial artery for coronary artery bypass grafting improves long-term outcomes: And now what?
}

\author{
Mario Gaudino, MD, MSCE, ${ }^{a}$ Paul Kurlansky, MD, ${ }^{b}$ and Stephen Fremes, MD
}

In the July 14, 2020, issue of the Journal of the American Medical Association, the Radial Artery Database International Alliance (RADIAL) consortium ${ }^{1}$ reported the longterm results of an individual patients' data meta-analysis including all the randomized controlled trials that compared the use of the radial artery (RA) with the saphenous vein (SV) as the second conduit for coronary artery bypass grafting (CABG) with a minimum follow-up of 2 years. The RADIAL investigators found that at a median follow-up of 10 years, the use of the RA was associated with a significant reduction in the incidence of the primary composite outcomes of death, myocardial infarction, or repeat revascularization (hazard ratio [HR], $0.73 ; 95 \%$ confidence interval $[95 \% \mathrm{CI}], 0.61-0.88)$ and of death or myocardial infarction (HR, 0.77; 95\% CI, 0.63-0.94) (Figure 1). Even though mortality was not a prespecified outcome and was evaluated post-hoc, the use of the RA was also associated with a significant reduction in 10-year mortality (HR, 0.73 ; 95\% CI, 0.57-0.93).

We herein briefly review the literature on the use of the RA and of multiple arterial grafts (MAGs) for CABG and discuss the adoption of MAG in clinical practice.

\section{THE RA IN CORONARY SURGERY}

The use of the RA for CABG was pioneered by Carpentier in the 1970s, but the artery was soon abandoned due to concerns of a high early failure rate. ${ }^{2}$ In the 1990s, the incidental discovery of perfectly patent RA grafts almost 20 years after the operation and the realization that most of the early angiographic findings were likely due to spasm due to competitive flow, lack of antispastic therapy, and a traumatic harvesting technique led to a renewed interest in the use of the conduit.

Since its reintroduction in coronary surgery, multiple studies have shown excellent mid- and long-term patency rates, especially when the RA is anastomosed to a target vessel with high-grade stenosis, and observational series

\footnotetext{
From the a Department of Cardiothoracic Surgery, Weill Cornell Medicine, New York, NY; 'bepartment of Surgery, Center for Innovation and Outcomes Research, Columbia University Medical Center, New York, NY; and ${ }^{\mathrm{c}}$ Division of Cardiac Surgery, Schulich Heart Centre, Department of Surgery, Sunnybrook Health Sciences Centre, University of Toronto, Toronto, Ontario, Canada.

Received for publication Aug 22, 2020; revisions received Sept 7, 2020; accepted for publication Sept 8, 2020; available ahead of print Nov 10, 2020

Address for reprints: Mario Gaudino, MD, MSCE, Department of Cardiothoracic Surgery, Weill Cornell Medicine, 525 East 68th St, New York, NY 10065 (E-mail: mfg9004@med.cornell.edu).

J Thorac Cardiovasc Surg 2021;162:1548-52

$0022-5223 / \$ 36.00$

Copyright (c) 2020 by The American Association for Thoracic Surgery

https://doi.org/10.1016/j.jtcvs.2020.09.143
}

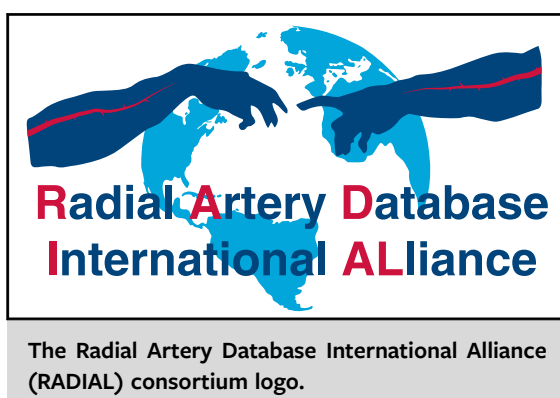

CENTRAL MESSAGE

The adoption of multiple arterial grafting remains low in the surgical community.

This Invited Expert Opinion provides a perspec tive on the following paper: JAMA. $2020 \mathrm{Jul}$ $14 ; 324(2): 179-187$

2020.8228

See Commentaries on pages 1553 and 1554 . have found longer survival in patients who receive an RA instead of an SV as the second conduit for $\mathrm{CABG}^{4}$ In a meta-analysis of 14 adjusted observational studies including more than 20,000 patients, we reported that at 6.6 years' follow-up, mortality was significantly lower in the RA group (incidence rate ratio, $0.74 ; 95 \% \mathrm{CI}, 0.63$ 0.87). ${ }^{5}$ However, observational comparative CABG studies are susceptible to treatment allocation and confounding bias, which could account for the reported difference. Surgeons tend to selectively use conduits with better longterm patency rate in patients who they consider will have a long-life expectancy according to their clinical judgement, and statistics can only adjust for measured confounders. ${ }^{6}$

The published randomized trials comparing the RA and the SV were powered for graft patency end points and individually underpowered to detect differences in clinical outcomes. The 5-year report from the RADIAL database found a significantly lower incidence of the composite outcome of death, myocardial infarction, or repeat revascularization in the RA arm, without differences in mortality and with a nominally statistically significant difference in myocardial infarction in favor of the RA without adjustment for multiple testing. ${ }^{7}$ Due to the relatively small sample size, the power of the 5-year RADIAL analysis was limited. Also, the 

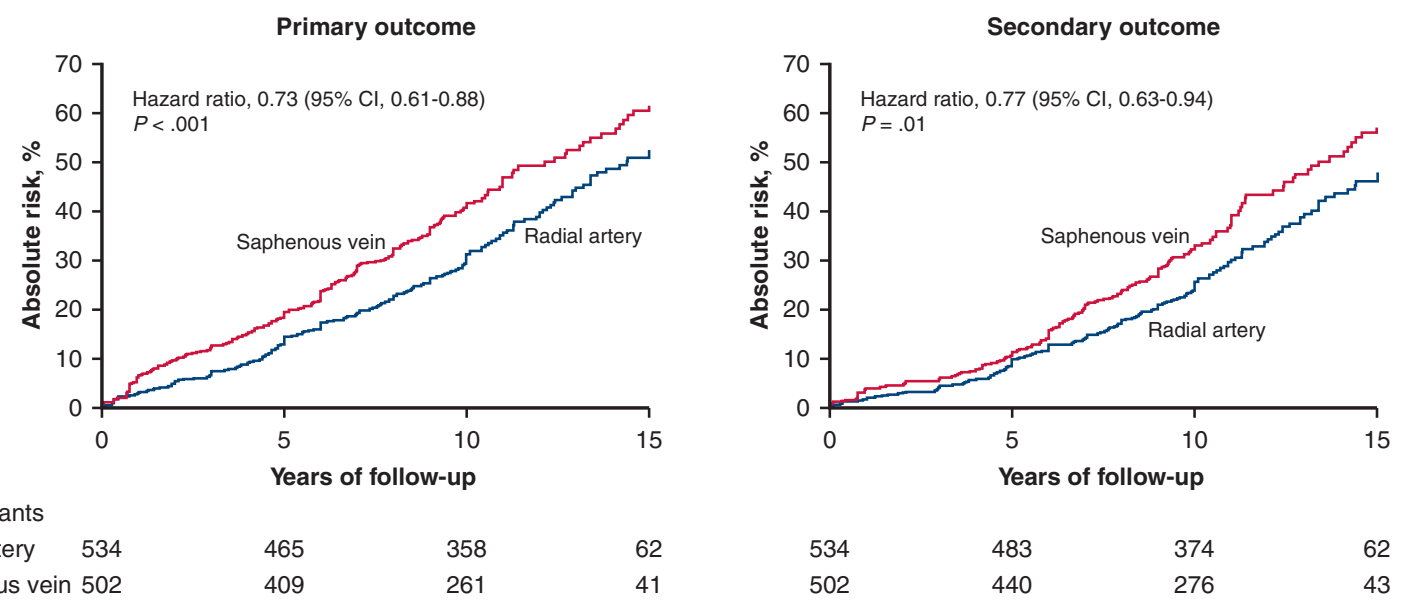

$\mathbf{A}$

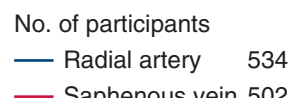

- Saphenous vein 502

A

FIGURE 1. Cumulative incidence of the (A) primary and (B) secondary composite outcomes at 10 years in the RADIAL database. CI, Confidence interval. Reproduced with permission from Gaudino and colleagues. ${ }^{1}$

use of per-protocol angiography by the majority of the trials in the first 5 years of the follow-up had likely inflated the event rate of the composite outcome. On the positive side, individual patients' data were obtained from randomized trials and the level of data collection was likely greater than in observational studies and the pooled analysis included all the published trials, itself relatively uncommon in individual patients' data meta-analyses.

The confirmatory results of the 10-year analysis were important because the majority of the included trials did not use per-protocol angiography after 5 years' follow-up (and so there was no artificial inflation of the event rate) and because, due to exponential increase in event rate during the follow-up of patients who underwent CABG, the power of the analysis was considerably greater than in the 5-year report and allowed testing of the prespecified hard clinically relevant outcomes.

\section{THE EVIDENCE ON THE USE OF MAG}

A large number of observational studies and metaanalyses have described increased late survival and improved cardiac outcomes in patients who receive bilateral internal thoracic arteries (BITA) and MAG. In one of the most recent meta-analyses, including 29 observational studies and a total of 89,399 patients, long-term survival was significantly increased in the BITA cohort (HR, 0.78; 95\% CI, 0.72-0.84) and operative mortality, stroke, and repeat revascularization were all significantly lower in the BITA group. ${ }^{8}$ In a meta-analysis of 25 , mostly observational, studies and 130,305 patients, Yanagawa and colleagues ${ }^{9}$ found that total arterial revascularization was associated with longer survival, and this result was consistent in both unadjusted and adjusted studies. In a metaanalysis of 8 propensity-matched studies (more than
10,000 patients) we have shown that the use of 3 arterial grafts was associated with longer survival compared with the use of 2 arterial grafts (HR, $0.8 ; 95 \%$ CI, 0.75-0.87). ${ }^{10}$

The Arterial Revascularization Trial (ART) is the only large randomized controlled trial that has tested the effect of BITA in patients who underwent CABG. In the intention-to-treat analysis, there was no difference in survival or event-free survival at 10 years between patients who received BITA or a single internal thoracic artery (HR, 0.96; 95\% CI, 0.82-1.12 and HR, 0.90; 95\% CI, 0.79-1.03, respectively). ${ }^{11}$ However, the high crossover rate (especially from the BITA to the control group), the unusually low morbidity of the patient population, the remarkably high compliance with optimal medical therapy, and the frequent $(>20 \%)$ use of the RA in the control group may have diluted the treatment effect in ART. In an observational analysis by number of arterial grafts, patients in ART receiving 2 or more arterial grafts had longer survival (adjusted HR, 0.81; 95\% CI, 0.68-0.95).

\section{ADOPTION OF MAG IN THE SURGICAL COMMUNITY}

The use of MAG for CABG has been disappointingly low over the course of the last 3 decades. In a report on 541,368 CABG cases in 745 hospitals in the Society of Thoracic Surgeons National Cardiac Database from 2002 through 2005, BITA use was $4 \%{ }^{12}$ and similar (or even lower) percentages were reported using other databases and in more recent years. ${ }^{13,14}$ Non-US countries generally reported greater MAG use: in the Australia New Zealand Cardiothoracic Database, more than 1 arterial graft was used in almost one-half $(48.6 \%)$ of the 34,213 isolated CABGs performed between 2004 and $2014,{ }^{15}$ and greater rates were reported in European and Canadian registries. ${ }^{16}$ We have recently 


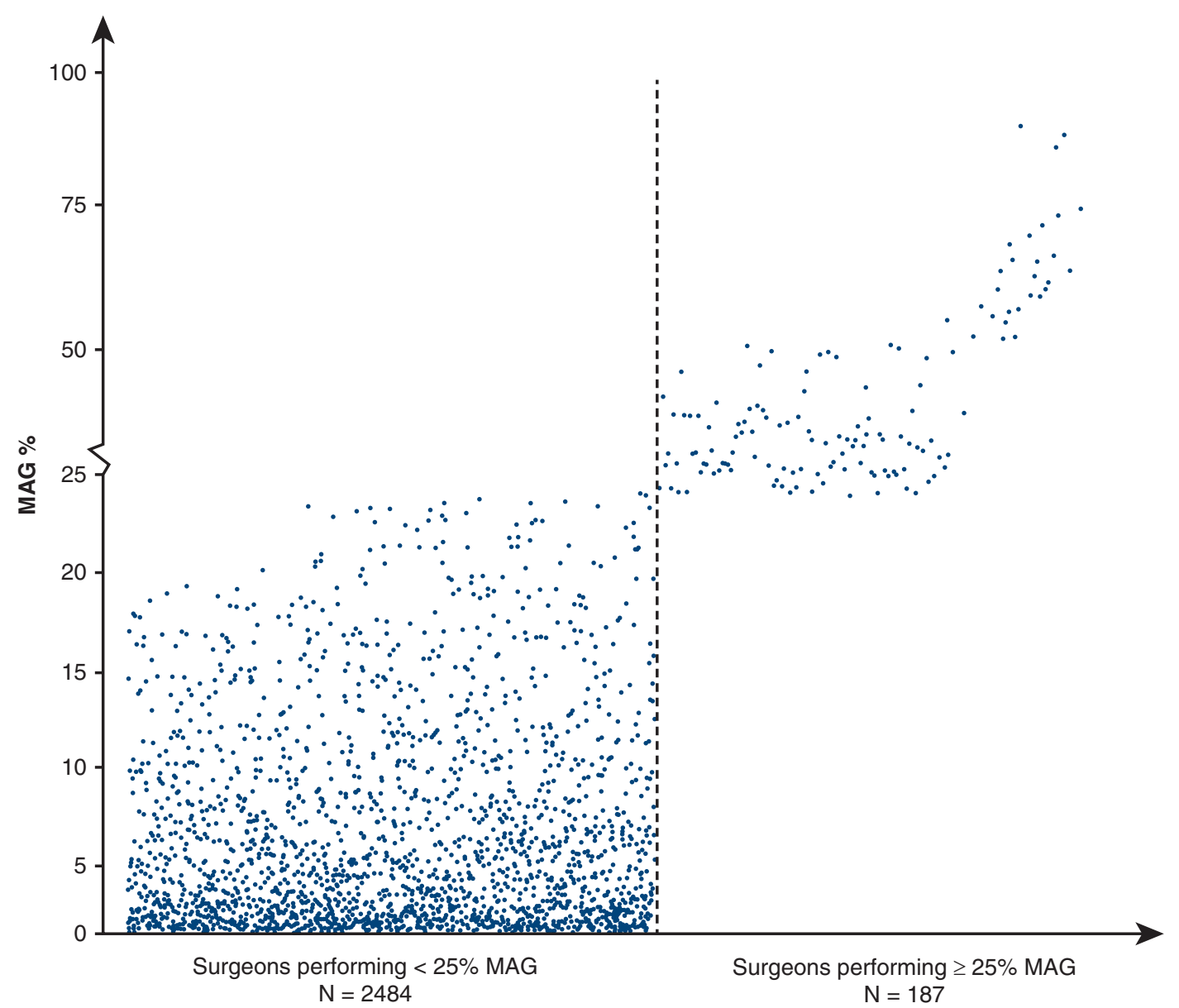

FIGURE 2. Individual surgeons' use rate of multiple arterial grafting in elective, low-risk patients 50 years older or younger in the Society of Thoracic Surgeons Database from 2008 to 2018. MAG, Multiple arterial grafts. Data for this figure were provided by The Society of Thoracic Surgeons' National Database Participant User File Research Program. Data analysis was performed at the Dr Gaudino's institution.

reported how in the Society of Thoracic Surgeons Database among 123,263 patients younger than 50 years without noncardiac comorbidities and undergoing elective primary isolated CABG (the ideal candidates for MAG) only $14.1 \%$ received more than one arterial graft. ${ }^{17}$ Of note, only $6 \%$ of the 2671 surgeons included in the analysis used MAG in more than $25 \%$ of the cases and a discouraging $1 \%$ used MAG in more than $50 \%$ of the patients even in this highly selected population (Figure 2).

So, the question at this stage of the knowledge is not so much if MAG improves clinical outcomes (probably yes, although a confirmatory trial is needed), but why the same surgeons who have embraced the use of the left internal mammary artery to left anterior descending coronary artery graft with considerably less confirmatory evidence are so reluctant to adopt MAG in their clinical practice.

Two surveys (both from the United Kingdom) have evaluated the opinions and the attitudes of surgeons toward the choice of conduits for CABG. ${ }^{18}$ The most frequently reported reason for the low adoption of MAG in both studies was the lack of clear evidence of its benefit. As we have discussed, the majority of the published studies supporting the use of MAG are observational and therefore subject to treatment allocation and other biases. For the RA, there has been no individual randomized trial with adequate sample size to evaluate clinical outcomes, although as described, the results of the RADIAL meta-analysis are encouraging. The results of the ART did not confirm a clinical benefit with the use of the BITA, acknowledging that the high crossover rate and the use of the RA in a high percentage of patients in the control group may have diluted the treatment effect.

However, it must be noted that other techniques have been adopted by the cardiac surgical community based on a level of evidence very similar to that existing for MAG. We have recently shown how the solidity of the observational evidence supporting the use of mitral valve repair versus replacement is similar to that supporting the use of MAG versus single arterial graft and valve-sparing versus Bentall root replacement. ${ }^{19}$ Mitral valve repair and valvesparing root replacement have not been tested in large 
randomized trials, but both are generally accepted as superior to their less-complex counterparts in eligible patients and adopted by the surgical community.

So, why are cardiac surgeons requiring a greater level of evidence supporting MAG to change their practice?

One important difference is the relative volumes of the 3 procedures. CABG is the most commonly performed adult cardiac surgery operations, accounting for more than 200,000 procedures in the United States only and ranking 14 th among the most frequent operating room procedures. ${ }^{20}$ Mitral valve procedures represent less than one-tenth of CABG volume and aortic root procedures around $2 \% .{ }^{20}$ The average American surgeon performs less than one mitral valve repair/month and for root procedures this number is around 2/year, whereas CABG is an almost-daily operation. ${ }^{21,22}$ A change from a simpler and faster procedure to a longer and more complex operation has a marginal effect to the practice of the average surgeon if the operation is performed a few times a year (as in the case of the mitral and aortic procedure) but has a very profound disruptive impact if the operation is performed on a daily basis. This may explain the higher bar that the surgical community seems to have set for the adoption of MAG compared with other procedures.

A second reason for the low rate of adoption of MAG in the UK surveys was the lack of confidence with the technique. It is true that complex MAG strategies such as anaortic $\mathrm{CABG}$ or composite grafts are generally not taught during training and require a greater level of technical expertise; it has been shown that, as in many other fields of surgery, a volume-outcome relationship exists for the use of BITA and off-pump CABG. ${ }^{23,24}$ Indeed, lack of familiarity with the technique becomes self-reinforcing, as lack of training results in surgeons who themselves do not further impart the knowledge. However, once certain key principles are established, the use of the RA is not technically different or more complex than the use of an SV, and it is something that every trained cardiac surgeon is able to master. MAG entails a wide variety of solutions of different technical complexity, although it does not seem that the technical aspect per se is the primary limitation to its widespread adoption. If technical issues alone were the barrier, one might well expect adoption of RA grafting to be much more warmly received approach to MAG than BITA grafting. However, neither approach is readily accepted. Going back to our analogy with mitral surgery, a robotic repair of a bileaflet prolapse is a technically challenging operation for dedicated specialists, but this does not mean that a conventional $\mathrm{P} 2$ repair should not be performed by the average surgeon.

So, we are back to the question of why the surgical community has been so reluctant to embrace MAG.

We believe that another reason is the lack of incentive and even a strong disincentive to the adoption of the technique in current practice. There is no doubt that when committing to MAG the surgeon has to accept its potential disadvantages, such as the more detailed preoperative assessment needed (in the case of the RA), the potentially increased risk of harvesting-site complications, and the longer operative time (particularly for BITA). The current health care system, especially in the United States, is mainly focused on productivity and short-term outcomes and rewards the number of procedures and the absence of complications rather than the quality of the intervention and the potential long-term benefits. Short-term outcomes are publicly reported and represent a main driver of patient referral.

The penalization that hospital and providers face in case of sternal wound complications, a rare but possible complication of BITA that is defined as never-event in the United States, is a paradigmatic example of the disincentive to MAG use in the current health care system.

While providing new and more solid confirmatory evidence of the benefit of MAG is very important, the adoption of new quality metrics focused on long-term outcomes and on the quality of the CABG procedure, rather than on productivity and operative outcomes, is in our opinion the real key to a wider adoption of MAG in surgical practice.

\section{Conflict of Interest Statement}

The authors reported no conflicts of interest.

The Journal policy requires editors and reviewers to disclose conflicts of interest and to decline handling or reviewing manuscripts for which they may have a conflict of interest. The editors and reviewers of this article have no conflicts of interest.

\section{References}

1. Gaudino M, Benedetto U, Fremes S, Ballman K, Biondi-Zoccai G, Sedrakyan A, et al. Association of radial artery graft vs saphenous vein graft with long-term cardiovascular outcomes among patients undergoing coronary artery bypass grafting: a systematic review and meta-analysis. JAMA. 2020;3242:179-87.

2. Carpentier A, Guermonprez JL, Deloche A, Frechette C, DuBost C. The aorta-tocoronary radial artery bypass graft. A technique avoiding pathological changes in grafts. Ann Thorac Surg. 1973;162:111-21.

3. Acar C, Jebara VA, Portoghese M, Beyssen B, Pagny JY, Grare P, et al. Revival of the radial artery for coronary artery bypass grafting. Ann Thorac Surg. 1992;544: 652-9; discussion 659-60.

4. Gaudino M, Fremes S, Schwann TA, Tatoulis J, Wingo M, Tranbaugh RF. Technical aspects of the use of the radial artery in coronary artery bypass surgery. Ann Thorac Surg. 2019;1082:613-22.

5. Gaudino M, Rahouma M, Abouarab A, Leonard J, Kamel M, Di Franco A, et al. Radial artery versus saphenous vein as the second conduit for coronary artery bypass surgery: a meta-analysis. J Thorac Cardiovasc Surg. 2019;1575: 1819-25.e10.

6. Gaudino M, Di Franco A, Rahouma M, Tam DY, Iannaccone M, Deb S, et al. Unmeasured confounders in observational studies comparing bilateral versus single internal thoracic artery for coronary artery bypass grafting: a meta-analysis. $J \mathrm{Am}$ Heart Assoc. 2018;7:e08010.

7. Gaudino M, Benedetto U, Fremes S, Biondi-Zoccai G, Sedrakyan A, Puskas JD, et al. Radial-artery or saphenous-vein grafts in coronary-artery bypass surgery. $N$ Engl J Med. 2018;37822:2069-77.

8. Buttar SN, Yan TD, Taggart DP, Tian DH. Long-term and short-term outcomes of using bilateral internal mammary artery grafting versus left internal mammary artery grafting: a meta-analysis. Heart. 2017;10318:1419-26. 
9. Yanagawa B, Verma S, Mazine A, Tam DY, Jüni P, Puskas JD, et al. Impact of total arterial revascularization on long term survival: a systematic review and meta-analysis of 130,305 patients. Int J Cardiol. 2017;233:29-36.

10. Gaudino M, Puskas JD, Di Franco A, Ohmes LB, Iannaccone M, Barbero U, et al. Three arterial grafts improve late survival: a meta-analysis of propensitymatched studies. Circulation. 2017;13511:1036-44.

11. Taggart DP, Benedetto U, Gerry S, Altman DG, Gray AM, Lees B, et al. Bilateral versus single internal-thoracic-artery grafts at 10 years. N Engl J Med. 2019; 3805:437-46.

12. Tabata M, Grab JD, Khalpey Z, Edwards FH, O’Brien SM, Cohn LH, et al. Prevalence and variability of internal mammary artery graft use in contemporary multivessel coronary artery bypass graft surgery: analysis of the Society of Thoracic Surgeons National Cardiac Database. Circulation. 2009;12011:935-40.

13. Iribarne A, Goodney PP, Flores AM, DeSimone J, DiScipio AW, Austin A, et al. National trends and geographic variation in bilateral internal mammary artery use in the United States. Ann Thorac Surg. 2017;1046:1902-7.

14. Schwann TA, Habib RH, Wallace A, Shahian DM, O'Brien S, Jacobs JP, et al Operative outcomes of multiple-arterial versus single-arterial coronary bypass grafting. Ann Thorac Surg. 2018;1054:1109-19.

15. Schwann TA, Tatoulis J, Puskas J, Bonnell M, Taggart D, Kurlansky P, et al. Worldwide trends in multi-arterial coronary artery bypass grafting surgery 2004-2014: a tale of 2 continents. Semin Thorac Cardiovasc Surg. 2017;293: 273-80.

16. Gaudino M, Chikwe J, Falk V, Lawton JS, Puskas JD, Taggart DP. Transatlantic editorial: the use of multiple arterial grafts for coronary revascularization in Europe and North America. Ann Thorac Surg. 2020;1096:1631-6.
17. Gaudino M, Rahouma M, Habib R, Hameed I, Robinson N, Farrington W, et al. Surgeons' coronary bypass practice patterns in the United States. J Am Coll Cardiol. 2020;76:1714-5.

18. Catarino PA, Black E, Taggart DP. Why do UK cardiac surgeons not perform their first choice operation for coronary artery bypass graft? Heart. 2002;886:643-4.

19. Gaudino M, Hameed I, Robinson N, Naik A, Weidenmann V, Ruan Y, et al. The robustness of the comparative observational evidence supporting Class I and II cardiac surgery procedures. J Am Heart Assoc. 2020;9:e016964.

20. McDermott KW, Freeman WJ, Elixhauser A. Overview of operating room procedures during inpatient stays in U.S. Hospitals, 2014: statistical brief \#233; 2006. In: Healthcare Cost and Utilization Project (HCUP) Statistical Briefs. Rockville, MD: Agency for Healthcare Research and Quality (US); 2006. Available at: http://www. ncbi.nlm.nih.gov/books/NBK487976/. Accessed August 15, 2020.

21. Stamou SC, Williams ML, Gunn TM, Hagberg RC, Lobdell KW, Kouchoukos NT. Aortic root surgery in the United States: a report from the Society of Thoracic Surgeons database. J Thorac Cardiovasc Surg. 2015;1491:116-22.e4.

22. Chikwe J, Toyoda N, Anyanwu AC, Itagaki S, Egorova NN, Boateng P, et al. Relation of mitral valve surgery volume to repair rate, durability, and survival. J Am Coll Cardiol. 2017;69:2397-406.

23. Gaudino M, Bakaeen F, Benedetto U, Rahouma M, Di Franco A, Tam D, et al. Use rate and outcome in bilateral internal thoracic artery grafting: insights from a systematic review and meta-analysis. J Am Heart Assoc. 2018;7:e009361.

24. Puskas JD, Gaudino M, Taggart DP. Experience is crucial in off-pump coronary artery bypass grafting. Circulation. 2019;13916:1872-5.

Key Words: CABG, radial artery, arterial grafting 